\title{
CONTEXTUALIZATION AND CONNECTIVITY OF DIGITAL LITERACY IN PRIMARY SCHOOL SOCIAL STUDIES DURING THE COVID-19 PANDEMIC
}

\author{
Siti Kowiyah ${ }^{1}$, Yatim Riyanto ${ }^{2}$, Harmanto ${ }^{3}$ \\ 1,2,3 Universitas Negeri Surabaya, Surabaya, Indonesia \\ sitikowiyah162@gmail.com
}

\begin{abstract}
This research identifies and explores Social Science (IPS) learning at the Elementary School level (SD) which is delivered by utilizing digital technology during the Covid-19 pandemic in Indonesia. This research is a qualitative study of digital literacy in social studies learning in elementary schools. The data sources were elementary school teachers using random sampling, with spatial boundaries in Surabaya and Sidoarjo, East Java. The temporal limitation of this research is data taken from April 2020 to January 2021. The collected data is then analyzed with Kathleen Tyner's perspective regarding literacy in the digital world and June Chapin about social studies learning in primary education. The results showed that contextuality and connectivity through digital literacy in elementary social studies raise constructive aspects through collective memory about experiencing something and using previous knowledge through digital literacy. The constructive and cognitive aspects present two essential dimensions that explain the occurrence of elementary social knowledge learning. First, relating to information processing; in terms of receiving, storing, and then remembering information when it has needed. Second, related to meaningful learning about social life in society, how children shape and organize existing and new information that comes to mind.
\end{abstract}

Keywords: digital literacy; social sciences learning; primary school

\section{KONTEKSTUALISASI DAN KONEKTIVITAS LITERASI DIGITAL PEMBELAJARAN ILMU PENGETAHUAN SOSIAL SEKOLAH DASAR DI MASA PANDEMI COVID-19}

\begin{abstract}
ABSTRAK
Penelitian ini mengidentifikasi dan mengeksplorasi pembelajaran Ilmu Pengetahuan Sosial (IPS) pada jenjang Sekolah Dasar (SD) yang disampaikan dengan memanfaatkan teknologi digital pada masa pandemi Covid-19 di Indonesia. Penelitian ini merupakan studi kualitatif terhadap fenomena literasi digital dalam pembelajaran IPS di Sekolah Dasar. Sumber data penelitain merupakan guru SD, dengan batasan spasial penelitian terletak di Surabaya dan Sidoarjo, Jawa Timur yang diambil secara acak menggunakan prinsip random sampling. Batasan temporal penelitian ini adalah data yang diambil pada bulan April 2020 hingga Januari 2021. Data yang telah terkumpul kemudian dianalisis dengan sudut pandang milik Kathleen Tyner tentang literasi dalam dunia digital, dan June Chapin tentang pembelajaran IPS dalam pendidikan dasar. Hasil penelitian menunjukkan bahwa kontekstualitas dan konektivitas yang dilakukan melalui literasi digital dalam pembelajaran IPS SD, memunculkan aspek konstruktif melalui memori kolektif tentang mengalami sesuatu dan menggunakan pengetahuan sebelumnya melalui literasi digital. Aspek konstruktif dan kognitif menyajikan dua dimensi penting yang menjelaskan terjadinya pembelajaran pengetahuan sosial SD. Pertama, berkaitan dengan pemrosesan informasi; dalam hal menerima, menyimpan, dan kemudian mengingat informasi saat dibutuhkan. Kedua, berkaitan dengan pembelajaran yang bermakna tentang kehidupan sosial bermasyarakat; dalam hal bagaimana anak-anak membentuk dan mengatur informasi yang ada dan baru yang muncul di benaknya.
\end{abstract}

Kata Kunci: literasi digital; pembelajaran ilmu pengetahuan sosial; sekolah dasar

\begin{tabular}{|c|c|c|}
\hline Submitted & Accepted & Published \\
\hline 08 Februari 2021 & 11 Mei 2021 & 25 Mei 2021 \\
\hline
\end{tabular}

\begin{tabular}{|l|c|r|r|}
\hline Citation & $:$ & $\begin{array}{r}\text { Kowiyah, S., Riyanto, Y., \& Harmanto, H. (2021). Contextualization And Connectivity Of Digital Literacy In Primary } \\
\text { School Social Studies During The Covid-19 Pandemic. Jurnal PAJAR (Pendidikan dan Pengajaran), 5(3), 703- } \\
\text { 709. DOI : http://dx.doi.org/10.33578/pjr.v5i3.8312. }\end{array}$ \\
\hline
\end{tabular}

\section{PENDAHULUAN}

Pendidikan dasar di Indonesia pada dasarnya seperti beberapa negara Asia Tenggara lainnya (Magat, 2014; Nokes, 2014). Pendidikan dasar direncanakan dan diatur untuk membantu peserta didik menerima dasar-dasar ilmu alam, sosial, dan kejuruan. Hal tersebut akan membantu peserta didik hidup dengan aman di komunitas lingkungan mereka, baik skala kecil maupun 
dalam skala yang lebih luas (Hung, 2020). Oleh karenanya, mata pelajaran yang diajarkan dalam pendidikan dasar dan metode pengajarannya harus ditinjau dari waktu ke waktu berdasarkan kebutuhan masyarakat ke depannya. Salah satu mata pelajaran yang dipelajari adalah dalam disiplin ilmu sosial humaniora yang terepresentasikan dalam mata pelajaran Ilmu Pengetahuan Sosial (IPS).

$$
\text { Ilmu Pengetahuan Sosial (IPS) }
$$

merupakan mata pelajaran yang pada hakekatnya melibatkan studi tentang masyarakat dan interaksi antar individu dalam masyarakat, dengan institusi sosial, politik, dan dengan lingkungan mereka (Herman, 1977). Mata pelajaran IPS dalam jenjang Sekolah Dasar (SD) adalah untuk memungkinkan siswa memahami, berpartisipasi, dan membuat keputusan yang tepat dan dalam kaitannya dengan masyarakat sosial sekitar (Winataputra, 2008). Konten IPS memungkinkan peserta didik SD untuk menjelaskan hubungan dengan orang lain, dengan institusi, dan lingkungan, serta membekali mereka dengan pengetahuan dan pemahaman tentang masa lalu (Dussel \& Priem, 2017). Hal tersebut akan memberi peserta didik keterampilan untuk pemecahan masalah yang produktif dan pengambilan keputusan. Lebih lanjut, untuk menilai masalah dan membuat penilaian nilai yang bijaksana berdasarkan pertimbangan sosial dan masyarakat.

Pendidikan IPS di SD mengintegrasikan keterampilan dan pemahaman terkait sosial dan masyarakat ke dalam kerangka kerja yang bersifat partisipatif sebagai warga yang bertanggung jawab secara lokal, nasional, dan global (Schroeder et al., 2020). Proses belajar mengajar dalam IPS pada hakekatnya diatur untuk mengembangkan kapasitas tersebut, dimulai dengan pendidikan dasar melalui literasi.

Literasi dalam pendidikan IPS di SD diartikan sebagai keterampilan, kemampuan, dan pengetahuan membaca yang sering disebut dengan literasi. Namun dalam konteks pendidikan IPS di SD, literasi mengalami perluasan makna di luar membaca dan menulis, terutama soal isu-isu dalam pembelajaran IPS. Pembelajaran IPS dalam gerakan literasi SD adalah keterampilan yang memungkinkan peserta didik membaca dunia tidak hanya melalui kata, kalimat, paragraf, atau wacana (Kosnik et al., 2016; Nuroh \& Liansari, 2018). Literasi SD saat ini sudah memasuki arena literasi digital, dengan melibatkan penggunaan berbagai bentuk komunikasi yang memberikan kesempatan lebih jauh dan lebih besar untuk memajukan diri sendiri, lingkungan sekitar, dan masyarakat (Brugar \& Roberts, 2018). Literasi digital membantu peserta didik SD memahami dunia dan mengungkapkan identitas, ide, dan budaya dalam konteks pembelajaran IPS.

Gerakan literasi digital dalam mempelajari IPS bagi peserta didik SD memerlukan model interdisipliner (Martin, 2008; Moran, 2002). Hal tersebut dikarenakan karakteristik peserta didik SD yang masih tergolong dalam masa anak-anak. Pembelajaran IPS dengan model yang menyenangkan akan memberikan pengalaman belajar yang turut serta berkontribusi dalam pengetahuan kolektif peserta didik. Lebih lanjut, mengingat bahwa saat ini peserta didik SD berada dalam era Generasi Z yang memiliki obsesi terhadap teknologi (Nuroh \& Liansari, 2018). Oleh karenanya perlu mempertimbangkan peran teknologi dalam proses pembelajaran IPS bagi peserta didik SD.

Fenomena tentang pemanfaatan teknologi dalam pembelajaran IPS bagi peserta didik SD mulai marak dilakukan pada tahun 2020, tepatnya ketika Covid-19 memasuki Indonesia (Sampurno et al., 2020). Hal tersebut sejalan dengan kebijakan pemerintah dalam mengantisipasi lonjakan kasus Covid-19 di bidang pendidikan, yaitu dengan menetapkan School From Home (SFH) (belajar dari rumah). Oleh karenanya, guru mulai melakukan transisi dalam moda pembelajaran konvensional tatap muka ke dalam moda pembelajaran modern dengan memanfaatkan teknologi digital.

Berpijak pada permasalahan di atas, penelitian ini ingin mengidentifikasi dan mengeksplorasi pembelajaran IPS pada jenjang SD yang disampaikan dengan memanfaatkan teknologi digital yang dalam ini adalah penggunaan internet, dan dialog literasi digital yang terjadi di dalamnya. Setelah didapatkan 
identifikasi dan eksplorasi penting terkait pembelajaran IPS pada jenjang SD dan dialognya dengan literasi digital, maka diharapkan penelitian ini mampu menjadi titik pijak baru dalam pengembangan model pembelajaran IPS berbasis digital. Hal ini mendukung perkembangan generasi dan model pembelajaran berbasis interdisipliner sehingga ke depannya mampu mempersiapkan materi dengan lebih matang dan tepat guna.

\section{KAJIAN TEORETIS}

Mata pelajaran Ilmu Pengetahuan Sosial (IPS) secara resmi mulai dipergunakan di Indonesia sejak tahun 1975 (Jones, 2012; Stevens, 2018; Sugiarta, 2007). Mata pelajaran IPS merupakan pengertian studi sosial mengenai segala sesuatu yang berhubungan dengan masyarakat. Di Indonesia, pelajaran IPS terutama di Sekolah Dasar memperlihatkan berbagai prespektif sosial yang berkembang di masyarakat secara sederhana (Herman, 1977; Howell \& Saye, 2016). Kajian tentang masyarakat dalam IPS dapat dilakukan dalam lingkungan yang terbatas, yaitu lingkungan sekitar sekolah atau antar peserta didik.

Guru di Sekolah Dasar memiliki cakupan yang umum, termasuk mengajarkan konsep pengetahuan sosial. Pembelajaran IPS dalam era milenial dan dengan peserta didik yang merupakan generasi $\mathrm{Z}$ memerlukan penggunaan teknologi dalam penyampaiannya. Hal tersebut sesuai dengan semangat literasi digital yang juga mendukung pembelajaran IPS untuk peserta didik $\mathrm{SD}$, yaitu (1) memperluas pembelajaran IPS dan melampaui apa yang dapat dilakukan tanpa teknologi; (2) memperkenalkan teknologi dalam konteks IPS; (3) mencakup kesempatan bagi peserta didik untuk mempelajari hubungan antara sains, teknologi, sosial, dan masyarakat; (4) membina pengembangan keterampilan, pengetahuan, dan partisipasi sebagai warga negara yang baik dalam masyarakat demokratis berbasis literasi dan teknologi digital; dan (5) berkontribusi pada penelitian dan evaluasi studi sosial dan teknologi (Chapin, 2014; Kosnik et al., 2016).
Literasi digital diartikan bahwa proses dan kegiatan membaca tidak hanya diartikan sebagai kemampuan membaca yang pada akhirnya mampu terjalin secara mendalam ke dalam jalinan mata pelajaran IPS di SD (Chapin, 2014; Tyner, 2009). Hal tersebut digunakan untuk menyediakan akomodasi dan modifikasi untuk kebutuhan pembelajaran yang beragam bagi peserta didik generasi Z. Literasi telah menjadi lebih dari sekedar kemampuan untuk membaca kata-kata tertulis dan definisinya terus berkembang dan bersifat paralel dengan perubahan dalam masyarakat, budaya, dan pendidikan (Iinuma, 2016; Tyner, 2009). Definisi telah mencakup deskripsi instruksi tradisional atau arahan dari keterampilan soal keaksaraan yang lebih dari standar minimum yang didefinisikan secara luas untuk pelajar abad ke-21 terutama generasi Z (Nuroh \& Liansari, 2018; Tyner, 2009).

Kemampuan literer atau keaksaraan terkait IPS tidak terbatas pada penguasaan kosakata, keterampilan perpustakaan dan referensi, strategi membaca, namun lebih pada siswa untuk menjadi pemikir mandiri dan pembelajar yang dapat mengingat dan menggunakan kembali apa yang telah mereka baca untuk mengumpulkan makna, berpikir kritis, dan memecahkan masalah adalah bagian dari literasi, yang tidak hanya melibatkan membaca, tetapi juga berbicara, mendengarkan, melihat, dan memahami semua bentuk materi yang terjadi dalam sosial masyarakat sekitar (Chapin, 2014; Kosnik et al., 2016; Tyner, 2009). Oleh karenanya, literasi digital dalam penelitian ini memiliki posisi yang aktual dan memiliki tingkat kebaruan, terutama ketika ditempatkan pada pembelajaran IPS di SD.

\section{METODE PENELITIAN}

Desain penelitian ini menggunakan prinsip penelitian kualitatif yang memanfaatkan data berbasis kata-kata deskriptif sebagai model utama baik dalam penulisan maupun analisis (Denzin \& Lincoln, 2018; Holladay \& Powell, 2018; Lune \& Berg, 2017). Penelitian kualitatif dipilih atas dasar pertimbangan bahwa penelitian 
tentang literasi digital dalam pembelajaran Ilmu Pengetahuan Sosial (IPS) dalam pendidikan jenjang Sekolah Dasar (SD) membutuhkan analisa secara tajam dan mendalam dengan penjabaran deskriptif agar memperjelas fenomena yang diteliti (Mills, 2019; J. Ross, 2017). Lebih lanjut, dengan menggunakan penelitian kualitatif, identifikasi dan eksplorasi akan menarik dilakukan karena memberikan penjabaran yang bersifat memperjelas tentang fenomena yang diteliti.

Untuk memberikan kemudahan dalam analisis, penelitian ini menggunakan teknik pengumpulan data dengan wawancara dan pengisian kuesioner. Kuesioner dalam penelitian ini tidak menjadi instrumen utama, namun berposisi sebagai metode komplementer yang membantu peneliti dalam membuat kajian deskriptif dan analitik terkait fenomena tentang literasi digital dalam pembelajaran IPS di SD (Mills, 2019; Shkedi, 2019). Kuesioner disebarkan dengan menggunakan platform Googleform yang diambil pada bulan Juni 2020 dan Desember 2020 pada alamat direktori surel yang terdaftar sebagai responden penelitian pada tahap pertama (Juni 2020).

Sumber data penelitian ini adalah peserta didik dan guru SD, dengan batasan spasial penelitian terletak di Surabaya dan Sidoarjo, Jawa Timur. Peserta didik dan guru SD yang menjadi sumber data penelitian diambil secara acak menggunakan prinsip random sampling. Hal tersebut bertujuan untuk mendapatkan data yang bersifat umum dari regional suatu wilayah. Batasan temporal penelitian ini adalah data yang diambil pada bulan April 2020 hingga Januari 2021 (observasi dan wawancara), serta pada Juni 2020 dan Desember 2020 (pengambilan kuesioner). Data yang telah terkumpul kemudian dianalisis dengan sudut pandang milik Kathleen Tyner (2009) tentang literasi dalam dunia digital, dan June Chapin (2014) tentang pembelajaran IPS dalam pendidikan dasar.

\section{HASIL DAN PEMBAHASAN}

Model pembelajaran IPS di SD mengacu pada konsepsi dasar terkait penjelasan tentang kurikulum dasar yaitu komunitas yang berelasi dengan diri, keluarga, negara, dan bangsa sebagai salah satu anggota masyarakat. Pembelajaran IPS dengan konsepsi tersebut melakukan perluasan makna melalui materi terkait kehidupan seharihari dan bermasyarakat kepada peserta didik SD. Pewacanaan yang dilakukan dalam penelitian ini melihat bahwa studi pengetahuan sosial dasar harus mencakup keterlibatan orang tua yang bertindak sebagai lembaga, yang memberikan batasan serta sudut pandang terhadap bidang kewarganegaraan, ekonomi, geografi, dan sejarah (Boyle-Baise et al., 2008). Hal tersebut pula yang dilakukan oleh guru di sekolah.

Berdasarkan survei terhadap 200 guru $\mathrm{SD}$, mengajar pelajaran IPS dengan mayoritas memberikan instruksi. Pengajaran difokuskan pada materi tentang kecakapan hidup bermasyarakat dan menggambarkan pengajaran mereka sebagai integrasi terhadap kehidupan sehari-hari di masyarakat. Mayoritas guru mencoba untuk memasukkan IPS ke dalam instruksi melalui membaca, menggunakan literatur IPS anak-anak untuk mengajarkan tentang masalah sosial dalam masyarakat. Ironisnya dengan model konvensional tersebut, sebagian besar mencoba untuk menutupi standar pelajaran IPS dengan instruksi singkat dan dangkal, yaitu dengan diskusi tanpa melakukan riset kecil dengan observasi lapangan. Kecenderungan literasi yang dilakukan, cenderung berada pada istilah membaca secara harfiah, yakni melalui menghargai keanekaragaman budaya, dan keterampilan membaca peta. Melalui gerakan literasi digital dan pemanfaatan teknologi, peserta didik tetap mampu menambah daya berpikir kritis dengan melakukan penelusuran digital terkait fenomena kehidupan sosial dan masyarakat sehari-hari (Akenson, 1989).

Pembelajaran yang selalu terfokus pada peserta didik, menarik benang merah terkait keterampilan guru. Guru era generasi Z, diharuskan memiliki kemampuan untuk memberikan stimulus kepada peserta didik untuk meningkatkan pemikiran kritis, perkembangan sosio-emosional, keterampilan prososial, interaksi interpersonal, dan literasi informasi (Hoffer, 2020; E. W. Ross et al., 2014). Melalui kompetensi 
tersebut, pembelajaran IPS di SD akan lebih bermakna dan berguna dan didukung dengan literasi digital yang dikembangkan dalam konteks studi sosial. Pemasukan literasi digital berbasis teknologi ke dalam studi pengetahuan sosial dasar juga mempersiapkan peserta didik sebagai warga negara yang aktif dan bertanggung jawab di abad 21, era disruptif, Internet of Thing (IoT), dan menuju era masyarakat 5.0, yang menuju konsepsi mengenai kewarganegaraan era digital (Nokes, 2014; Parker, 2016).

\section{Tabel 1. Literasi Digital Berbasis Teknologi dalam Pembelajaran IPS SD}

\begin{tabular}{|c|c|c|c|}
\hline Kelas & Guru & $\begin{array}{l}\text { Rerata } \\
\text { pengalaman } \\
\text { (dalam tahun)* }\end{array}$ & Pemanfaatan Teknologi (dari yang paling sering)** \\
\hline 1 & 28 & 5.7 & $\begin{array}{l}\text { Group WhatsApp, browsing internet, YouTube, platform kelas } \\
\text { daring, platform pihak ke-3 }\end{array}$ \\
\hline 2 & 33 & 6.0 & $\begin{array}{l}\text { Group WhatsApp, browsing internet, YouTube, platform kelas } \\
\text { daring, platform pihak ke-3 }\end{array}$ \\
\hline 3 & 31 & 6.3 & $\begin{array}{l}\text { Group WhatsApp, platform kelas daring, browsing internet, } \\
\text { YouTube, platform pihak ke-3 }\end{array}$ \\
\hline 4 & 35 & 6.5 & $\begin{array}{l}\text { Group WhatsApp, platform kelas daring, YouTube, browsing } \\
\text { internet, platform pihak ke-3 }\end{array}$ \\
\hline 5 & 38 & 6.3 & $\begin{array}{l}\text { Group WhatsApp, platform kelas daring, YouTube, browsing } \\
\text { internet, platform pihak ke-3 }\end{array}$ \\
\hline 6 & 35 & 6.7 & $\begin{array}{l}\text { Group WhatsApp, platform kelas daring, YouTube, browsing } \\
\text { internet, platform pihak ke-3 }\end{array}$ \\
\hline Total & 200 & $6.25 *$ & **Rerata pemanfaatan teknologi: 5 platform/cara/media \\
\hline
\end{tabular}

Keterampilan guru dalam menghadapi pembelajaran IPS dengan memanfaatkan literasi digital berbasis teknologi pada dasarnya telah dimulai sebelum masa pandemi Covid-19. Pasca merebaknya pandemi Covid-19 di Indonesia, pemanfaatan teknologi berkembang pesat baik dari pemanfaatan paltform, cara penyampaian berbasis daring, atau media dalam pembelajaran yang digunakan (Tabel 1) (Sampurno et al., 2020). Generalisasi penggunaan teknologi digital dalam penyampaian literasi terkait mata pelajaran IPS tidak dipengaruhi oleh lama pengalaman guru mengajar. Baik guru senior maupun guru yang baru bekerja di lembaga sekolah sudah memanfaatkan teknologi digital dalam penyampaian materi.

Dari berbagai macam platform, cara penyampaian, dan media penyampaian materi,
Group WhatsApp tetap menjadi primadona (Tabel 1). Hal tersebut dikarenakan efektivitas dan efisiensi, mengingat WhatsApp adalah platform pengolah pesan populer di Indonesia. Meskipun popularitas WhatsApp hampir diimbangi oleh Telegram, namun pada pembelajaran di SD, WhatsApp tetap menjadi pilihan pertama sebagai media pembelajaran daring, baik dengan penyampaian materi, rekaman suara, pesan teks (chat), dan media tukar media gambar. Selanjutnya guru memanfaatkan platform kelas daring sepertihalnya Google Meets dan Zoom Meeting. Hal tersebut dikarenakan dengan platform tersebut, interaksi dapat berjalan hampir sepertihalnya kelas tatap muka. Pembeda terletak pada pembelajaran pengetahuan sosial di kelas 1 , di mana guru menganggap pembelajaran dengan browsing internet lebih efektif daripada 
Jurnal PAJAR (Pendidikan dan Pengajaran)

Volume 5 Nomor 3 April 2021 | ISSN Cetak : 2580 - 8435| |ISSN Online : 2614 - 1337

DOI : http://dx.doi.org/10.33578/pjr.v5i3.8312

menggunakan Google Meets atau Zoom Meeting

(Tabel 1).
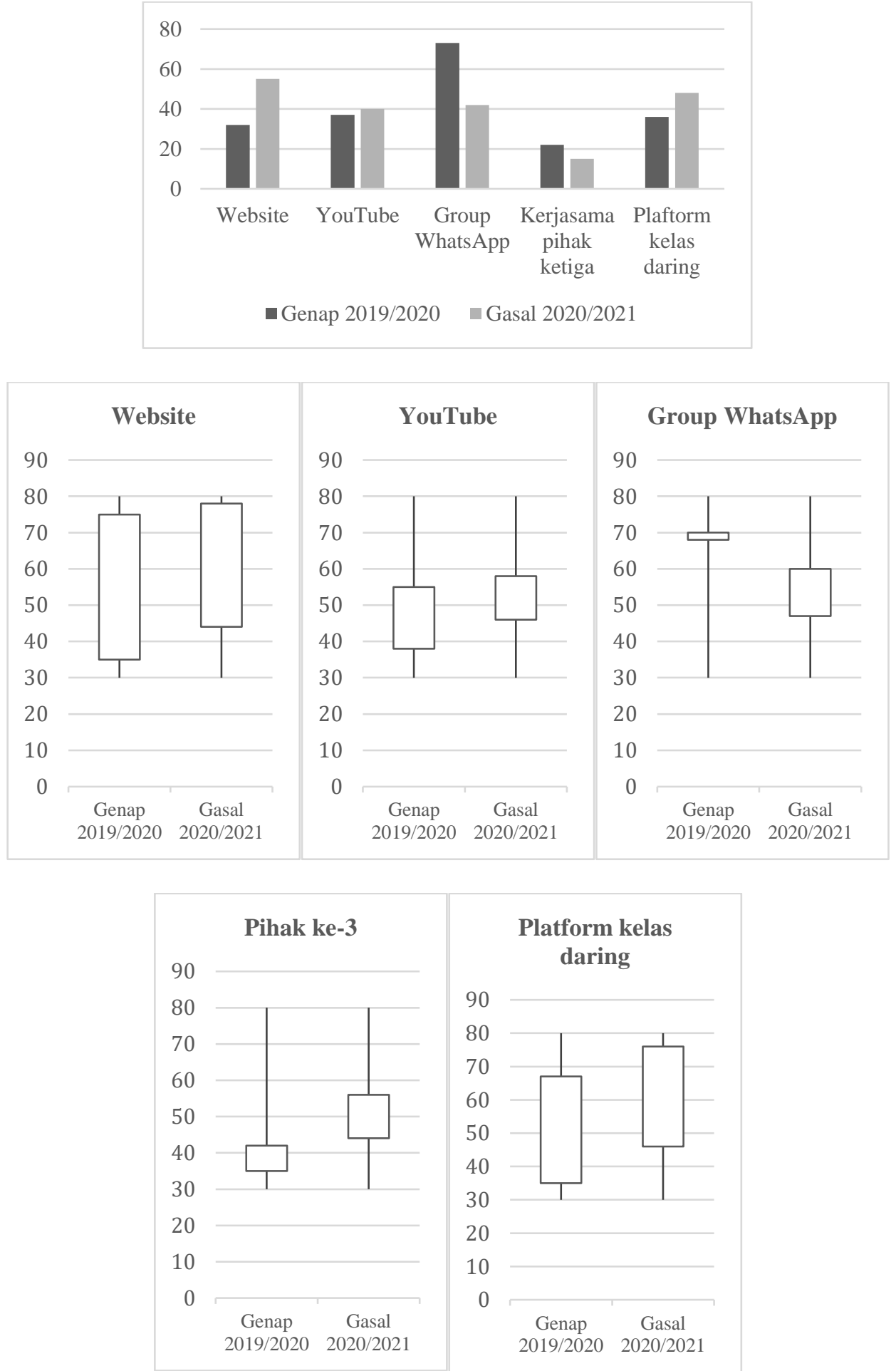

Gambar 1. Perkembangan Penggunaan Platform Media Pembelajaran IPS 
Terdapat perubahan terkait media pembelajaran IPS, di mana pada semester Genap 2019/2020, Group WhatsApp mendominasi sebagai media pembelajaran daring. Namun pada semester Gasal 2020/2021 guru telah beradaptasi terhadap pemanfaatan teknologi, dengan lebih memaksimalkan website-website belajar, YouTube, dan didukung dengan tatap muka virtual melalui Google Meets dan Zoom Meeting (Gambar 1).

Penggunaan platform tatap muka virtual mampu memaksimalkan diskusi kelompok secara terarah dan mereduksi kurangnya prioritas yang diberikan pada pengajaran IPS dan penekanan pada membaca, menulis, dan berbicara (berdiskusi) untuk memenuhi kebutuhan peserta didik (Chapin, 2014). Guru menunjukkan bahwa alokasi waktu untuk literasi digital memberikan kelonggaran untuk pengajaran IPS dalam mengeksplorasi materi tentang fenomena yang akan disampaikan. Di kelas rendah maupun tinggi, pelajaran IPS adalah cara atau metode lain untuk melatih strategi membaca, terutama yang terkait dengan sejarah, namun dengan literasi digital materi tersebut bisa tereksplorasi dengan maksimal. Lebih lanjut, materi yang dianggap sebagai studi sosial yang aktual sepertihalnya penanganan Covid-19 oleh komunitas kecil dalam masyarakat menunjukkan ketergantungan pada berbagai bentuk pembelajaran. Peserta didik memeriksa teks-teks dan fenomena tertentu dan mendiskusikan apa yang mereka baca melalui periode tanya jawab dadakan melalui kelas virtual.

Transisi penggunaan teknologi dalam pembelajaran IPS SD menuju model yang lebih interaktif dengan menggunakan Google Meets dan Zoom Meeting didasarkan pada pewacanaan terhadap dua teori pembelajaran yaitu kontekstualitas dan konektivitas. Mengacu dengan apa yang dikatakan oleh Kathleen Tyner tentang literasi dalam dunia digital bahwa guru akan selalu bergerak dinamis dalam proses adaptasinya ketika guru berada dalam lingkungan sosial yang menjadi kewajibannya (Tyner, 2009). Di dalam penelitian ini, posisi guru berada dalam poros sentral, di mana guru merupakan individu yang terlegitimasi dalam struktur masyarakat untuk melakukan diseminasi pengetahuan ilmu sosial kepada peserta didik SD. Oleh karenanya, guru berusaha untuk meningkatkan kompetensi untuk melakukan tugasnya, yang kali ini didukung dengan penggunaan teknologi. Terkait literasi digital, dengan proses adaptasi yang cepat, guru mampu memberikan materi yang sesuai kepada peserta didik terkait pembelajaran IPS di SD.

Literasi digital pembelajaran IPS di SD merupakan perujudan dari percakapan informal yang dilakukan sebelum dan sesudah pelajaran dengan model diskusi (Franklin \& Molebash, 2007; Whitlock \& Brugar, 2019). Guru merasa berkewajiban untuk lebih memfokuskan waktu pengajaran mereka ke dalam bentuk yang mendukung kemampuan membaca, mengobservasi, dan berdiskusi meskipun dilakukan secara virtual.

Model adaptasi ini mencakup kontekstualitas dan konektivitas untuk membawa peserta didik SD melalui perjalanan praktik mental dari mengamati objek dan fenomena literasi digital dan memeriksa materi nyata ke pembelajaran IPS yang berkontribusi dalam memori kolektif jangka panjang peserta didik (Csikszentmihalyi, 2018; Schroeder et al., 2020). Kontekstualitas literasi digital dalam pembelajaran IPS di SD terjadi ketika pembelajaran yang berfokus pada berbagai aspek nyata dari setiap lingkungan pembelajaran yang menjadi objek literasi digital, baik di ruang kelas, laboratorium, atau arena sosial virtual (Gambar 2).

Kontekstualitas terkoneksi dengan prinsip konektivitas yang dikembangkan sebagai hasil dari keyakinan bahwa ada kebutuhan akan norma terkait hidup bermasyarakat, tata krama dalam masyarakat, dan hal dasar dalam masyarakat, yang memperhitungkan cara masyarakat berubah sebagai akibat dari era digital bagi peserta didik SD (Chen, 2014; Strachan, 2015). Kontekstualitas dalam pembelajaran menempatkan peserta didik belajar dalam situasi nyata atau di tempat yang dekat dengan situasi nyata. Literasi digital pembelajaran IPS memberikan pemahaman baru dan aktual yang membantu peserta didik memahami pelajaran, menciptakan ide-ide baru, 
dan menghubungkan antara mata pelajaran akademik dengan konsep dunia nyata dalam sosial masyarakat melalui kontekstualitas dan konektivitas (Gambar 2). Kontekstualitas dan konektivitas tersebut berupaya membantu peserta didik dalam pengembangan praktek bermasyarakat saat ini melalui desain pembelajaran IPS yang dikembangkan berbasis sarana digital dimasa yang akan datang (Kissling \& Bell, 2020; Payne, 2017).

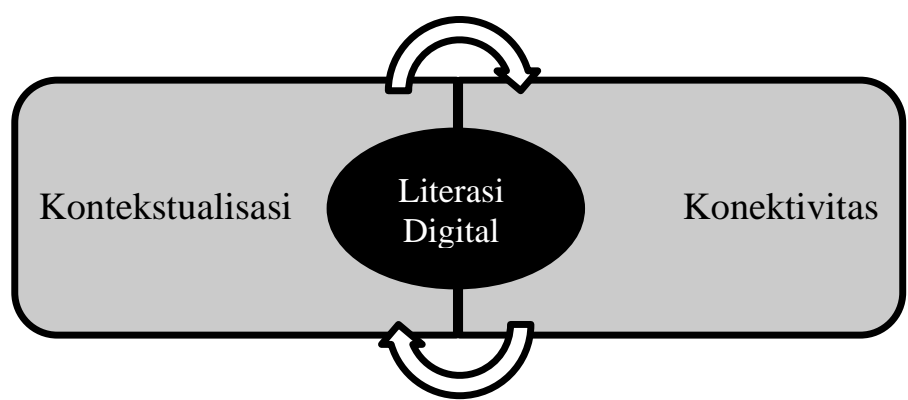

\section{Gambar 2. Inter-relasi Literasi Digital Dalam Interaksi Kontekstualitas dan Konektivitas Pembelajaran IPS SD}

\begin{abstract}
Kontekstualitas dan konektivitas yang dilakukan melalui literasi digital dalam pembelajaran IPS SD, memunculkan aspek konstruktif melalui memori kolektif tentang mengalami sesuatu dan menggunakan pengetahuan sebelumnya melalui literasi digital (Houser, 1996; Hung, 2020). Lebih lanjut, kontekstualitas dan konektivitas yang memunculkan aspek konstruktif pada akhirnya menstimulasi aspek kognitif peserta didik (Brugar \& Roberts, 2018; Dinkelman \& Cuenca, 2020). Aspek kognitif menyajikan dua dimensi penting yang menjelaskan terjadinya pembelajaran pengetahuan sosial SD. Pertama, berkaitan dengan pemrosesan informasi; dalam hal menerima, menyimpan, dan kemudian mengingat informasi saat dibutuhkan. Kedua, berkaitan dengan pembelajaran yang bermakna tentang kehidupan sosial bermasyarakat; dalam hal bagaimana anak-anak membentuk dan mengatur informasi yang ada dan baru yang muncul di benaknya. Di dalam hubungan kontekstualitas dan konektivitas terdapat beberapa peran yang dapat dilakukan oleh guru dan peserta didik secara bersama-sama. Berbagai peran tersebut melalui fase model, di mana model ini dapat difungsikan untuk mengajar dan mempelajari materi pelajaran apa pun terkait IPS di tingkat sekolah dasar.
\end{abstract}

\section{SIMPULAN DAN REKOMENDASI}

Pembelajaran IPS di SD dengan literasi digital menunjukkan bahwa tingkat dan kualitas pendidikan guru merupakan faktor penting bagi efektivitas guru. Efektivitas penyampaian materi dan pemanfaatan teknologi berperan penting terutama dalam pendidikan era milenial bagi generasi Z. Dengan memanfaatkan literasi digital berbasis teknologi, guru menunjukkan bahwa apa daya berpikir kritis dapat diterapkan secara maksimal dalam pengaturan kelas mereka meski secara daring karena adanya pandemi Covid-19. Kurangnya penerapan dan kurangnya kelayakan persiapan guru tampaknya tidak berlaku untuk para guru SD dalam penelitian ini mengenai persiapan mereka untuk mengajar dengan teknologi. Para guru terus menggunakan teknologi dengan cara yang lebih baik dari kebanyakan guru SD yang sering dipersepsikan oleh masyarakat selama ini.

Penggunaan literasi digital berbasis teknologi mampu menghubungkan kesiapan, visi, dan integrasi teknologi dengan persiapan guru terhadap materi IPS yang akan diberikan. Di dalamnya, muncul aspek kontekstualitas dan konektivitas sebagai siklus interaktif yang mengitari literasi digital. Literasi digital pembelajaran IPS di SD merupakan perujudan dari percakapan informal yang dilakukan sebelum 
dan sesudah pelajaran dengan model diskusi. Guru merasa berkewajiban untuk lebih memfokuskan waktu pengajaran mereka ke dalam bentuk yang mendukung kemampuan membaca, mengobservasi, dan berdiskusi meskipun dilakukan secara virtual. Model adaptasi ini mencakup kontekstualitas dan konektivitas untuk membawa peserta didik SD melalui perjalanan praktik mental dari mengamati objek dan fenomena literasi digital dan memeriksa materi nyata ke pembelajaran IPS yang berkontribusi dalam memori kolektif jangka panjang peserta didik. Kontekstualitas literasi digital dalam pembelajaran IPS di SD terjadi ketika pembelajaran yang berfokus pada berbagai aspek nyata dari setiap lingkungan pembelajaran yang menjadi objek literasi digital, baik di ruang kelas, laboratorium, atau arena sosial virtual. Kontekstualitas terkoneksi dengan prinsip konektivitas yang dikembangkan sebagai hasil dari keyakinan bahwa ada kebutuhan akan norma terkait hidup bermasyarakat, tata krama dalam masyarakat, dan hal dasar dalam masyarakat, yang memperhitungkan cara masyarakat berubah sebagai akibat dari era digital bagi peserta didik SD. Hal ini memberikan pengalaman dalam pembelajaran yang menempatkan peserta didik belajar dalam situasi nyata atau di tempat yang dekat dengan situasi nyata.

Rekomendasi penelitian ini terletak pada literatur untuk mempersiapkan guru dalam mengintegrasikan teknologi ke dalam pengajaran mereka termasuk: (a) mengintegrasikan teknologi di seluruh pengalaman guru, dan (b) menyediakan model integrasi teknologi yang efektif, terutama dalam literasi digital di semua mata pelajaran yang diawali dengan mata pelajaran bernuansa sosial humaniora. Kolaborasi antara teknologi, pendidikan, dan literasi menghasilkan teknologi pendidikan era generasi $\mathrm{Z}$ yang diintegrasikan dalam mata pelajaran IPS. Dengan mengintegrasikannya, fokus tetap terletak pada konten materi IPS bukan pada teknologi yang digunakan. Hal ini akan menghasilkan berbagai macam strategi pengajaran yang berlabuh dalam konten studi sosial. Oleh karenanya, perlu sosialisasi dan workshop terkait pemanfaatan teknologi agar studi sosial bisa disampaikan secara luas dan masif sehingga kompetensi terkait literasi digital dan teknologi berfungsi sebagai landasan awal bagi guru yang ingin menjadikan teknologi sebagai bagian yang lebih integral dari pembelajaran yang dilakukan.

\section{DAFTAR PUSTAKA}

Akenson, J. E. (1989). The expanding environments and elementary education: A critical perspective. Theory and Research in Social Education, 17(1), 33-52. https://doi.org/10.1080/00933104.1989.1050 5578

Boyle-Baise, M., Hsu, M. C., Johnson, S., Serriere, S. C., \& Stewart, D. (2008). Putting reading first: Teaching social studies in elementary classrooms. Theory and Research in Social Education, 36(3), 233-255. https://doi.org/10.1080/00933104.2008.1047 3374

Brugar, K. A., \& Roberts, K. L. (2018). Elementary students' challenges with informational texts: Reading the words and the world. Journal of Social Studies Research, 42(1), 49-59. https://doi.org/10.1016/j.jssr.2017.02.001

Chapin, J. R. (2014). Elementary Social Studies: A Practical Guide. Pearson.

Chen, W. (2014). Psychological needs satisfaction, motivational regulations and physical activity intention among elementary school students. Educational Psychology, 34(4), 495-511. https://doi.org/10.1080/01443410.2013.8229 59

Csikszentmihalyi, M. (2018). Flow: The Psychology of Optimal Experience. Harvard University Press. https://doi.org/wiretap

Denzin, N. K., \& Lincoln, Y. S. (Eds.). (2018). The SAGE Handbook of Qualitative Research (Fifth Edit). Sage Publications. https://doi.org/10.1007/s11229-017-1319-x

Dinkelman, T., \& Cuenca, A. (2020). A turn to practice: Core practices in social studies teacher education. Theory and Research in Social Education, 48(4), 583-610. 
https://doi.org/10.1080/00933104.2020.1757 538

Dussel, I., \& Priem, K. (2017). The visual in histories of education: A reappraisal. Paedagogica Historica, 53(6), 641-649. https://doi.org/10.1080/00309230.2017.1392 582

Franklin, C. A., \& Molebash, P. E. (2007). Technology in the elementary social studies classroom: Teacher preparation does matter. Theory and Research in Social Education, $35(2)$,

153-173. https://doi.org/10.1080/00933104.2007.1047 3331

Herman, W. L. (1977). Teacher behavior in the elementary school social studies. Theory and Research in Social Education, 5(3), 39-63. https://doi.org/10.1080/00933104.1977.1050 6014

Hoffer, E. R. (2020). Case-based teaching: Using stories for engagement and inclusion. International Journal on Social and Education Sciences, 2(2), 75-80. https://files.eric.ed.gov/fulltext/EJ1263931.p df

Holladay, P. J., \& Powell, R. B. (2018). SocialEcological Resilience and Stakeholders: A Qualitative Inquiry into Community-Based Tourism in the Commonwealth of Dominica. Carribean Studies, 44(1), 3-28.

Houser, N. O. (1996). Negotiating Dissonance and Safety for the Common Good: Social Education in the Elementary Classroom? Theory and Research in Social Education, 24(3), 294-312. https://doi.org/10.1080/00933104.1996.1050 5780

Howell, J. B., \& Saye, J. W. (2016). Using lesson study to develop a shared professional teaching knowledge culture among 4th grade social studies teachers. Journal of Social Studies Research, 40(1), 25-37. https://doi.org/10.1016/j.jssr.2015.03.001

Hung, Y. H. (2020). Exploration of teachers' personal practical knowledge for teaching controversial public issues in elementary school classrooms. Journal of Social Studies
Research, 44(3), 281-289. https://doi.org/10.1016/j.jssr.2020.04.001

linuma, M. (2016). Learning and Teaching with Technology in the Knowledge Society: New Literacy, Collaboration and Digital Content. Springer Singapore.

Jones, T. (2012). Indonesian Cultural Policy in the Reform Era. Indonesia, 93(93), 147-176.

Kissling, M. T., \& Bell, J. T. (2020). Teaching social studies amid ecological crisis. Theory and Research in Social Education, 48(1), 131.

https://doi.org/10.1080/00933104.2019.1673 267

Kosnik, C., White, S., Beck, C., Marshall, B., Lin Goodwin, A., \& Murray, J. (Eds.). (2016). Building Bridges: Rethinking Literacy Teacher Education in a Digital Era. Sense Publishers. https://doi.org/10.1007/978-946300-491-6

Lune, H., \& Berg, B. L. (2017). Qualitative Research Methods for the Social Sciences (Ninth edit). Pearson.

Magat, M. C. (2014). In Search of Southeast Asian Folklorists. Western Folklore, 73(2-3), 280-296.

Martin, A. (2008). Digital Literacy and the Digital Society. Die Deutsche Bibliothek.

Mills, K. A. (2019). Big Data for Qualitative Research. In Routledge Focus. Routledge. https://doi.org/10.4324/9780429056413

Moran, J. (2002). Interdisciplinarity. Routledge.

Nokes, J. D. (2014). Elementary students roles and epistemic stances during documentbased history lessons. Theory and Research in Social Education, 42(3), 375-413. https://doi.org/10.1080/00933104.2014.9375 46

Nuroh, E. Z., \& Liansari, V. (2018). Digital Age Literacy in Elementary School. 1st International Conference on Intellectuals' Global Responsibility, 125(ASSEHR), 119123. https://doi.org/10.2991/icigr-17.2018.29

Parker, C. (2016). Pedagogical Tools for Peacebuilding Education: Engaging and Empathizing with Diverse Perspectives in Multicultural Elementary Classrooms. Theory and Research in Social Education, 
44(1),

104-140.

https://doi.org/10.1080/00933104.2015.1100 150

Payne, K. A. (2017). Democratic teacher education in elementary classrooms Learning about, through, and for thick democracy. Journal of Social Studies Research, 41(2), 101-115. https://doi.org/10.1016/j.jssr.2016.07.001

Ross, E. W., Mathison, S., \& Vinson, K. D. (2014). Social Studies Education and Standards-Based Education Reform in North America: Curriculum Standardization, HighStakes Testing, and Resistance. Revista Latinoamericana de Estudios Educativos (Colombia), 10(1), 19-48.

Ross, J. (2017). Speculative method in digital education research. Learning, Media and Technology, 42(2), 214-229. https://doi.org/10.1080/17439884.2016.1160 927

Sampurno, M. B. T., Kusumandyoko, T. C., \& Islam, M. A. (2020). Budaya Media Sosial, Edukasi Masyarakat, dan Pandemi COVID19. SALAM: Jurnal Sosial Dan Budaya SyarI, $7(5)$. https://doi.org/https://doi.org/10.15408/sjsbs. v7i5.15210

Schroeder, S., Murray-Everett, N. C., Gates, J., \& Shear, S. B. (2020). Informing, transforming, inquiring: Approaches to elementary social studies in methods course syllabi. Journal of Social Studies Research, xxxx, 1-16. https://doi.org/10.1016/j.jssr.2020.07.001

Shkedi, A. (2019). Introduction to Data Analysis in Qualitative Research. Springer International Publishing.

Stevens, M. L. (2018). Culture and Education. Annals of the American Academy of Political and Social Science, 619(1), 97-113. https://doi.org/10.1177/0002716208320043

Strachan, S. L. (2015). Kindergarten students' social studies and content literacy learning from interactive read-alouds. Journal of Social Studies Research, 39(4), 207-223. https://doi.org/10.1016/j.jssr.2015.08.003

Sugiarta, A. N. (2007). Pengembangan Model Pengelolaan Program Pembela-jaran
Kolaboratif Untuk Kemandirian Anak Jalanan Di Rumah Singgah (Studi Terfokus di Rumah Singgak Kota Bekasi). Universitas Pendidikan Indonesia.

Tyner, K. (2009). Literacy in A Digital Wo. Routledge.

Whitlock, A. M. M., \& Brugar, K. A. (2019). Teaching elementary social studies during snack time and other unstructured spaces. Journal of Social Studies Research, 43(3), 229-239.

https://doi.org/10.1016/j.jssr.2018.09.007

Winataputra, U. S. (2008). MultikulturalismeBhinneka Tunggal lka Dalam Perspektif Pendidikan Kewarganegaraan Sebagai Wahana Pembangunan Karakter Bangsa Indonesia. In Jurnal Pendidikan dan Kebudayaan (Vol. 14, Issue 75, pp. 10091027).

https://doi.org/10.24832/jpnk.v14i75.364 